\title{
Effects of happy emotion induced by Filipino children's music on the performance in addition and subtraction of grade in Filipino Pupils
}

\author{
Michael Molina Nael \\ Philippine Normal University, Philippines \\ Corresponding author: mike_nael@yahoo.com
}

DOI: https://doi.org/10.37134/jrpptte.vol9.no1.4.2019

Received: 09 May 2019; Accepted: 23 May 2019; Published: 17 June 2019

\begin{abstract}
This study sought to identify Filipino children's music that can induce happy emotion through a survey, to develop emotion-based teaching aids utilizing the identified music and to find out if the use of the emotion-based teaching aids can improve the performance in addition and subtraction of grade 1 Filipino pupils. The results of the survey showed that nine out of the ten Filipino children's music were able to induce happy emotion by registering an overall statistically significant difference $(t(199)=32.53, s d=.282, m=.65$, $p=<.001$ ) between the antecedent and consequent emotions of pupils. These music were; 1. Jack en poy, 2. Leron, Leron Sinta, 3. Pen Pen de serapen, 4. Kumusta, Kumusta, 5. Lubi, Lubi, 6. Sitsiritsit, 7. Kung Ikaw ay Masaya, 8. Magtanim ay di biro and 9. Paruparung bukid. While the results of the experiment failed to support the null hypothesis because the experimental group registered statistically significant improvements over the control group $(\mathrm{t}(70)=-3.50, m=-1.58, s d=3.90, p=.001)$. at .05 significant level. This result was strengthened by the statistically significant difference in the subjects' periodic grade $(t(70)=-4.20, m=-.92, s d=1.90, p=<.001)$. So, even though there were observed statistically significant improvement in the performance of the control group in addition $(t$ $(70)=-7.04, m=-1.04, s d=1.23, p=<.001)$, Subtraction $(t(70)=-7.47, m=-1.65, s d=$ $1.86, p=<.001)$ and periodic grades $(t(40)=-8.67, m=-1.29, s d=.96, p=<.001)$, the overall performance of the experimental group was better than the control group. The study concluded that happy emotion induced by the identified Filipino children's music improved the performance in addition and subtraction of grade 1 pupils. The study recommended to policy makers to formulate guidelines to effectively incorporate emotion-based teaching in the classrooms and recommended to teachers, school heads and administrators to recognize and actually employ emotions in the teaching-learning process.
\end{abstract}

Keywords: Filipino children's music, emotion-based teaching aids, happy emotion, performance

\section{INTRODUCTION}

Schooling is an emotionally laden process for students, teachers and parents (Schutz, Hong, Cross \& Osborne, 2006). Students experience a range of emotions in academic settings which include topic, social and epistemic emotions (Rowe, Fitness \& Wood, 2014). Social emotions arise in response to social concerns (Hareli \& Parkinson, 2008) while epistemic emotions are experienced in response to the knowledge-generating qualities of cognitive activities (Pekrun, Vogl, Muis \& Sinatra, 2017). Vail (2016) posited that the emotional brain, the limbic system, opens or closes access to learning, memory and the ability to make novel connections. There appears to be consensus among recent researches that emotions do influence learning (Pekrun \& Linnenbrink-Garcia, 2014) which may be useful for the design of effective educational curricula to provide a conducive learning environment (Tyng, Amin, Saad \& Malik., 2017). Furthermore, emotions are not only the product of the processing of information by the brain, but they directly influence the processes of learning 
and memory in the brain (Tendler \& Wagner, 2015). Learners who were induced with positive mood had higher learning outcomes in comprehension and transfer tests. (Park, Knörzer, Plass, \& Brünken, 2015). When learners were made aware of their emotions, when guided by specific teaching strategies and when teachers were conscious of students' emotional state their attitude and feedback became more effective and the learners' performance improves (Arguedas, Daradoumis \& Xhafa, 2016) Furthermore, positive emotions which are marked by contentment, enthusiasm, and enjoyment in the present moment (Seligman, 2011) have been linked to the acquisition of various skills that foster academic success. Cultivating happiness in the classroom has been suggested to help students sustain a sense of resilience, mindfulness, and even physical health (Fredrickson, Cohn, Coffey, Pek \& Finkel, 2008). The basic positive emotions of joy activated by the familiar face of their mother and of interest and joy are equally essential to survival, evolution, and development of children (Izard, Stark, Trentacosta, \& Schultz, 2008).

However, when a student is under stress, the majority of the brain shuts down and reverts to survival needs, such as defensiveness and attention-seeking (Weare, 2004). On the other hand, several researchers have examined math anxiety in empirical studies since the introduction of the term mathemaphobia to describe the phobia-like feelings of many towards mathematics (SuárezPellicioni, Núñez-Peña, \& Colomé, 2016). Some other discrete negative emotions found to be important in academic contexts include anxiety, fear, frustration, anger, boredom, sadness, shame, hopelessness, guilt and embarrassment (Rowe, Fitness \& Wood, 2015).

Emotions constitute potent, pervasive, predictable, sometimes harmful and sometimes beneficial drivers of decision making (Lerner, Li, Valdesolo \& Kassam, 2015) and understanding the impact of emotions both positive and negative is important in developing better teaching practices, promoting strategies and managing the teaching-learning process which can in turn lead to improved learning outcomes (Diener \& Biswas-Diener, 2008). There is a need for teachers to devise some intervention plan specifically related to difficulties in emotion regulation in order to assist students to improve their learning and performance (Singh, Singh \& Singhal, 2013). There are still untapped benefits for educators who still do not use the power of emotion to effect learning even though, these educators knew that the learning process is mediated by the learner's emotion (Liew \& Tan, 2016).

But the study of Schwartz, Ayres and Douglas (2017) on learning with background music showed for the first time the neural underpinnings of the implicit processing of brief musical emotions, particularly in front oparietal, dorsolateral prefrontal, and striatal areas of the brain. While McEwing (2011) outlined the ways teachers can use music through songs that are familiar to gain confidence in their own skills by using songs, chants, and dances that teachers have known since their school days and Thomson, Schellenberg and Letnic (2012) revealed that the characteristics of music like tempo and intensity influenced the learning outcomes when they found that soft fast music had a positive influence but loud fast as well as soft slow or loud slow music hindered learning. In addition, Perham and Currie, (2014) found that instrumental music disturbs learners less than music with lyrics. On the other hand, studies on music for young children found that math gains increase according to the number of years that students engage in music (Gardiner, 2000) and that the younger the children engaged in music, the greater the gains. The children's overall performance on the number sense and their growth rate between kindergarten and first grade predicted the overall performance and the growth rate in mathematics achievement (Jordan, Kaplan, Ramineni \& Locuniak, 2009) while early facility with addition and subtraction number combinations was most predictive of later achievement Jordan, Kaplan, Locuniak \& Ramineni, 2007).

Since the mathematical achievements of Filipino students were very low as shown by the achievement rate of grade VI students in Mathematics at the National Achievement Test (NAT) from 2008 to 2012 that ranges from $63.26 \%$ to $68.43 \%$ and which saw a decline in the year 2013 to $66 \%$ (Department of Education, 2013). The modern theories and pedagogies introduced in the K- 12 program which focused more on cognitive strategies may not be enough. The mounting evidences found in the studies in other countries on the beneficial effects of emotion in learning may hold the key to the effective and efficient learning of mathematical skills and to improvements in the performance of Filipino pupils. The use of induced happy emotions through music may be a better alternative to the current focus on rational practices that demotes the role of emotions in learning 
even though its use may be more suited in the Philippine setting since Filipinos are generally perceived to be music lovers, cheerful and emotional rather than rational in their dispositions (Jocano, 2000).

Thus, the overarching objective of this research was to develop emotion-based teaching aids aimed to improve the performance in addition and subtraction of grade 1 pupils through happy emotion induced by background music and from this it set out to pursue the following specific objectives:

1. To identify Filipino children's music that induce happy emotion;

2. To develop emotion-based teaching aids utilizing Filipino children's music played as background to induce happy emotions that shall improve the performance in addition and subtraction of grade 1 Filipino pupils; and

3. To determine if the pupils who were taught using the emotion-based teaching aids that induced happy emotion through Filipino children's music performed better than those who did not use the emotion-based teaching aids.

In order to achieve all these, answers to the following questions were sought:

Research Question 1: Is there any Filipino children's music than induces happy emotion? Research Question 2: Were the performances in Addition and Subtraction of the Music group better than the control group?

And the following hypotheses were tested in this study:

Ho 1: There is no statistically significant difference in the antecedent and the consequent emotions induced by Filipino children's music.

Ho 2: There is no statistically significant difference in the performance in addition and subtraction of the control and the experimental groups

\section{RESEARCH DESIGN}

This research conducted surveys, developed teaching aids and conducted an experiment using emotion-based teaching aids that consisted of five lessons in addition and five lessons in subtraction. The survey and the experiment were conducted for ten days- five days for addition lesson and five days for subtraction lessons in two schools in Manila, Philippines.

The pretest-posttest design was employed in this study to determine if the intervention had caused better performance in the participants. Since the pupils were subjected to the same lessons with different treatments any significant differences in the performance of the two groups were likely from the intervention (Blair, Czaja \& Blair, 2013). The validity and reliability of the instruments and the teaching aids were insured by attempting to have high face validity, concurrent validity and predictive validity through the employment of a single-blind study where the participant does not know the condition, they are in. This method ensured there was little demand characteristics, such as trying to behave a certain way because they think that is what is expected of them. The Cronbach's alpha method was used in order to determine the reliability of the instruments and the learning aids. The teaching aids and instruments were also subjected to expert validation, pilot testing using different groups and by comparing the results to find out if the teaching aids and the instruments can generate consistent results.

The teaching aids developed by the researcher were evaluated by twenty-five teachers of grade 1 pupils from different schools in Manila and pilot tested to sixty grade 1 pupils from Fernando Ma. Guerrero Elementary school in Manila. Thirty pupils were randomly drawn from a class assigned as the control group and thirty pupils were randomly drawn from a class assigned to the experimental group. These two classes involved in the pilot testing were not part of the survey and the experiment. 
The survey involved two hundred grade 1 pupils $(N=200)$ whose classes were randomly selected from the grade 1 classes of Fernando Ma. Guerrero Elementary School. The pupils involved 97 male (48.50\%) and 103 females (51.50\%). The initial emotions of the pupils were taken by using the music questionnaire and afterwards the pupils were made to listen to several traditional Filipino children's music. The antecedent and the consequent emotions were compared through a paired ttest of the mean of differences to identify the music that induces happy emotion using SPSS version 23 at .05 significant level and the experiment involved one hundred fifty-three pupils $(N=153)$ whose classes were randomly selected and divided into the control and the experimental groups. The control group $(n=70)$ were taught with addition and subtraction lessons without the use of music to induce happy emotion. The experimental groups $(n=83)$ were taught using the emotion-based teaching aids developed by the researcher with the Filipino children's music used as background.

This research involved five phases. Phase 1 identified the music that induced happy emotion and the math competencies to be used in the development of the teaching aids. This phase developed the music questionnaire, the emotion-based teaching aids and the Pre \& Post Tests.

Phase 2 evaluated, validated and pilot tested the instruments and the teaching aids. Twentyfive expert teachers and sixty grade 1 pupils established the validity and reliability of the instruments and the teaching aids.

Phase 3 included the formulation of guidelines, the training of teachers and the implementation of the experiment. In the experiment, one group of respondents was taught without any intervention to serve as the control group. The second group was taught using the teaching aid that utilized background music.

Phase 4 was the data collection stage which included the conduct of the pre and posttests. The results of the tests were collected and tabulated. Statistical treatments were done to find out how much learning did each group attained. The mean differences per group were compared to determine if there were statistically significant differences in the rate of improvement in each group's performance. In this phase also, the teaching aids were evaluated by the participating teachers in terms of module design, content, relevance and usefulness.

The last phase, analyzed the results and presented the findings according to the questions raised. From these findings, implications, conclusions and recommendations were inferred and suggested.

\section{FINDINGS, ANALYSES AND DISCUSSIONS}

I. Findings on Research Question 1: Is there any Filipino children's music that induce happy emotion?

\section{a. Statistically significant difference between antecedent and consequent emotions were found}

Table 1. The Mean, Standard Deviation, the Mean Difference and the Significant Paired T-Test Value of Emotions Felt Before and After Listening to Music

\begin{tabular}{lccccc}
\hline & mean & $S d$ & $t$ & $d f$ & sig(2tailed) \\
\hline Before Music & 3.83 & .198 & & & \\
After Music & 4.48 & .306 & & & \\
Difference & .65 & .282 & 32.53 & 199 & .000 \\
\hline
\end{tabular}

Results presented in Table 1 showed that the emotion after listening to music ( $m=4.48, s d=.306, n$ 
$=200)$, recorded an increase in the mean as compared to the emotion before listening to music $(\mathrm{m}$ $=3.83, s d=.198, n=200$ ). This indicated that there was a statistically significant difference between the emotion felt before and after listening to music at $t(199)=32.53, s d=.282, m=.65, p=<.001$. This result showed that the null hypothesis failed to be accepted and its alternative must be accepted. There were Filipino children's music that induced happy emotion. Thus, statistical evidence was found that the subjects felt happier after listening to these music. It also showed that these Filipino children's music may be utilized in the emotion-based teaching aids to induce happy emotion in an attempt to improve the pupils' performance in addition and subtraction.

\section{b. There were Filipino children's music that induced happy emotion}

Table 2. Difference in the antecedent and consequent emotions felt by grade 1 pupils on listening to specific Filipino Children's music

\begin{tabular}{llccccc}
\hline & \multicolumn{1}{c}{$\begin{array}{c}\text { Emotion before } \\
\text { and after music }\end{array}$} & Mean & std. deviation & $t$ & $d f$ & $\begin{array}{c}\text { sig } \\
\text { (2-tailed) }\end{array}$ \\
\hline Pair 1 & JACK AND POY & -.915 & .901 & -14.362 & 199 & .000 \\
Pair 2 & KUMUSTA, KUMUSTA & -.935 & .771 & -17.160 & 199 & .000 \\
Pair 3 & KUNG IKAW AY ... & -.965 & .999 & -13.656 & 199 & .000 \\
Pair 4 & LERON, LERON SINTA & -.955 & .791 & -17.068 & 199 & .000 \\
Pair 5 & LUBI, LUBI & -.375 & .571 & -9.288 & 199 & .000 \\
Pair 6 & MAGTANIM AY DI... & -.965 & .621 & -21.974 & 199 & .000 \\
Pair 7 & PEN PEN & -.305 & .560 & -7.703 & 199 & .000 \\
Pair 8 & SITSIRITSIT & -.845 & .650 & -18.372 & 199 & .000 \\
Pair 9 & PARU-PARUNG BUKID & -.535 & .686 & -11.023 & 199 & .000 \\
Pair 10 & MAY TATLONG BIBI & -.045 & .596 & -1.068 & 199 & .287 \\
\hline
\end{tabular}

Results on Table 2 showed that there were nine songs, with a $p=<.001$ at .05 significant level, that registered statistically significant difference in the emotion felt by the pupils before and after listening to them. These were; 1. Jack enpoy, 2.L eron, Leron Sinta, 3. Pen Pen de serapen, 4. Kumusta, Kumusta, 5. Lubi, Lubi, 6. Sitsiritsit, 7. Kung Ikaw ay Masaya, 8. Magtanim ay di biro and 9. Paru-parung bukid. Of the top ten traditional Filipino children's music in the survey, only May tatlong bibi did not registered statistically significant difference at $p=.287$.

\section{c. Some Filipino music can induce opposite or change the intensity of an emotion}

Table 3. Frequency of emotions felt by respondents before and after listening to Filipino Children's Music

\begin{tabular}{ccccccccccccccc}
\hline & \multicolumn{1}{c}{$\begin{array}{c}\text { Very } \\
\text { Sad }\end{array}$} & \multicolumn{3}{c}{ Sad } & \multicolumn{1}{c}{ Neutral } & \multicolumn{3}{c}{ Happy } & \multicolumn{2}{c}{ Very } \\
& E1 & E2 & E1 & E2 & E1 & E2 & E1 & E2 & E1 & E2 & E1 & E2 & dif & $R$ \\
\hline Music 1 & 0 & 4 & 8 & 3 & 24 & 7 & 168 & 18 & 0 & 168 & 3.80 & 4.72 & .92 & 5 \\
Music 2 & 2 & 8 & 7 & 2 & 29 & 7 & 162 & 18 & 0 & 167 & 3.76 & 4.69 & .93 & 4 \\
Music 3 & 0 & 5 & 19 & 5 & 31 & 13 & 150 & 15 & 0 & 162 & 3.66 & 4.62 & .97 & 1 \\
Music 4 & 0 & 2 & 9 & 5 & 29 & 10 & 162 & 13 & 0 & 170 & 3.77 & 4.72 & .95 & 3 \\
Music 5 & 0 & 1 & 0 & 0 & 18 & 4 & 186 & 132 & 0 & 63 & 3.91 & 4.28 & .37 & 8 \\
Music 6 & 0 & 3 & 13 & 1 & 29 & 5 & 158 & 37 & 0 & 154 & 3.73 & 4.69 & .97 & 2 \\
\hline
\end{tabular}




\begin{tabular}{ccccccccccccccc}
\hline Music 7 & 1 & 0 & 0 & 0 & 1 & 0 & 198 & 200 & 0 & 0 & 3.98 & 4.00 & .02 & 10 \\
Music 8 & 0 & 4 & 6 & 1 & 29 & 10 & 165 & 33 & 0 & 152 & 3.80 & 4.64 & .84 & 6 \\
Music 9 & 0 & 2 & 6 & 1 & 17 & 5 & 177 & 101 & 0 & 91 & 3.86 & 4.39 & .53 & 7 \\
Music 10 & 0 & 0 & 2 & 0 & 3 & 0 & 195 & 200 & 0 & 0 & 3.97 & 4.00 & .03 & 9 \\
Total & 3 & 26 & 70 & 18 & 210 & 61 & 1721 & 767 & 0 & 1127 & 3.82 & 4.48 & .65 & \\
\hline
\end{tabular}

Legend: Music $1=$ Jack enpoy

Music 2=Kumusta, Kumusta

Music 3=Kung Ikaw ay masaya

Music 10=May Tatlong Bibi

\author{
Music 4=Leron, LeronSinta \\ Music 5=Lubi, Lubi \\ Music 6=Magtanim ay di biro \\ E1=Emotion before music
}

\author{
Music $7=$ Pen Pen de serapen \\ Music $8=$ Sitsiritsit \\ Music 9=Paru-parungbukid \\ E2= Emotion after music
}

Table 3 showed a marked increase in the frequency of those who became "very happy" after listening to music number 4 (Leron, Leron Sinta) which registered an increase in frequencies from $f=0$ to 170. However, music number 7 (Pen Pen De Serapen) and music number 10 (May Tatlong Bibi) barely registered change in the emotion originally felt by the pupils ( $f=195$ and 198- happy to $f=200$ "happy").

The highest mean of emotion felt before music was recorded in music number 7 (Pen Pen De Serapen, $m=3.98$ - "happy") but the music was not able to change the emotion to very happy. The lowest mean before music belonged to music number 3 (Kung Ikaw ay Masaya, $m=3.66=$ "happy"), however it recorded the highest difference in the change to very happy emotion felt by the pupils after listening to the music.

On the other hand, the highest means after music were recorded by music number 1 (Jack En Poy) and music number 4 (Leron Leron Sinta) both with a mean of $4.72=$ "very happy" while the lowest mean after music went to music number 10 (May Tatlong Bibi, $m=4.00=$ "hapy"). The highest mean difference between the emotions before and after music were given to music number 3 (Kung Ikaw ay Masaya, dif=.97) and music number 6 (Magtanim ay Di Biro, dif= .96) while the lowest was given to music number 7 (Pen Pen De Serapen, dif=.02)

\section{d. There was difference on the emotions felt by the males and the females as induced by Filipino children's music}

Table 4. Differences in the means of emotions felt before (E1) and after (E2) Music as to Sex

\begin{tabular}{|c|c|c|c|c|c|c|c|}
\hline \multirow{2}{*}{$\begin{array}{c}\text { Sex } \\
\text { Music }\end{array}$} & \multirow[b]{2}{*}{$\begin{array}{c}\text { mean } \\
\text { E1 }\end{array}$} & \multirow{2}{*}{$\begin{array}{c}\text { Male } \\
\text { mean E2 }\end{array}$} & \multicolumn{3}{|c|}{ Female } & \multirow[b]{2}{*}{ dif } & \multirow{2}{*}{$\begin{array}{c}\text { total } \\
\text { mean } \\
\text { dif }\end{array}$} \\
\hline & & & dif & mean E1 & $\begin{array}{c}\text { mean } \\
\text { E2 }\end{array}$ & & \\
\hline Music 1 & 3.83 & 4.63 & .80 & 3.77 & 4.81 & 1.04 & .92 \\
\hline Music 2 & 3.65 & 4.57 & .92 & 3.86 & 4.82 & .96 & .93 \\
\hline Music 3 & 3.68 & 4.55 & .87 & 3.63 & 4.70 & 1.07 & .97 \\
\hline Music 4 & 3.76 & 4.73 & .97 & 3.77 & 4.71 & .94 & .95 \\
\hline Music 5 & 3.83 & 4.55 & .72 & 4.00 & 4.00 & 0 & .37 \\
\hline Music 6 & 3.70 & 4.66 & .96 & 3.75 & 4.72 & .97 & .96 \\
\hline Music 7 & 4.00 & 4.00 & 0 & 3.96 & 4.00 & 04 & .02 \\
\hline Music 8 & 3.76 & 4.56 & .80 & 3.83 & 4.73 & .90 & .84 \\
\hline Music 9 & 3.89 & 4.07 & .18 & 3.81 & 4.74 & .93 & .53 \\
\hline Music 10 & 4.07 & 4.00 & .07 & 4.00 & 4.00 & 0 & .03 \\
\hline Total & 3.82 & 4.43 & .63 & 3.84 & 4.52 & .68 & .65 \\
\hline
\end{tabular}

$\begin{array}{cll}\text { Legend: } \text { Music1=Jack enpoy } & \text { Music 4=Leron, LeronSinta } & \text { Music 7=Pen Pen de serapen } \\ \text { Music 2=Kumusta, Kumusta } & \text { Music 5=Lubi, Lubi } & \text { Music 8=Sitsiritsit } \\ \begin{array}{c}\text { Music 3=Kung Ikaw ay masaya } \\ \text { Music 10=May Tatlong Bibi }\end{array} & \text { Music 6=Magtanim ay di biro } & \text { Music 9=Paru-parungbukid } \\ & \text { E1=Emotion before music } & \text { E2=Emotion after music }\end{array}$

Table 4 showed that the initial emotions of the male $(m=3.82)$ and female $(m=3.84)$ pupils were similar and both sexes were initially "happy" but there was a noticeable increase in the mean of 
females who felt from "happy" to "very happy" after listening to music (from $m=3.84$ to 4.52 ). The males remained "happy" even though there was a .63 increase in the mean after listening to music.

These findings on research question 1 are in agreement with the arousal-mood-hypothesis of Husain et al, (2002) which suggested that some music have positive and stimulating effect, which could improve the pupil's performance in addition and subtraction. Additionally, Helmrich (2010) suggested that the impact of music most often has been identified specifically in relation to math. The current finding identifying the specific Filipino children's music and their ability to induce happy emotion provides a tool to Filipino teachers to counteract math anxiety which causes low performance in math. So instead of being anxious the teacher can induce happy emotion of the pupils through these songs so that better learning and performance in math may be achieved.

Perhaps the characteristics of these Filipino children's music of being soft and fast and not loud and fast as well as soft and slow or loud and slow could have been the reasons why they were able to induce the positive emotion happy that influenced the learning outcome, since according to Thomson, Schellenberg and Letnic (2012) the music's characteristics like tempo and intensity influenced learning outcomes: only soft fast music had a positive influence, whilst loud fast as well as soft slow or loud slow music hindered learning. Although, these Filipino children's music were with lyrics which Perham and Currie (2014) considered to be more disturbing to the learners than instrumental music, it appeared that the disturbances created by the lyrics of these Filipino children's music were not enough to drastically affect or change the positive emotion outcome brought about by the music.

The pupils were relatively happy as shown by the antecedent emotions of the male and female pupils. While there was a noticeable increase after listening to music in the mean of females who felt from "happy" to "very happy". The males remained "happy" even though there was an increase in the mean after listening to music. It seemed that the background music affected the females more than the males. This finding was congruent with the findings of other studies that female adolescents were more likely than male adolescents to use music to reflect their emotional state, in particular when feeling lonely or "down" (Roberts \& Christensen, 2001) while male adolescents were more likely to use music as a stimulant, as a way to boost their energy level, or to create a more positive image of themselves (North, Hargreaves \& O'Neill,2000). According to Simon and Nath, (2004) men report calm feelings more frequently than do women, who more frequently report feelings of anxiety, sadness and anger. In addition, it was also found that women tend to express themselves with more emotional terms than men who are more apt to use cognitive and perceptual terms (Bauer, Stennes \& Haight, 2003). The female language also is more elaborate and affective while male language is more direct, succinct and instrumental (Mulac, Bradac \& Gibbons, 2001).

I. Findings on Research Question 2: Were the performances in Addition and Subtraction of the music group better than the control group?

\section{a. There were differences on the sums of the scores of the experimental and the control groups}

Table 5. Sum and mean of Pre-test, Post test Scores and of the $1^{\text {st }}$ and $2^{\text {nd }}$ Grading Grades of the Control group and the Music Group

\begin{tabular}{|c|c|c|c|c|c|c|c|c|c|c|c|c|c|c|}
\hline \multirow{3}{*}{ Groups } & \multicolumn{6}{|c|}{ Pre-Test Scores } & \multicolumn{6}{|c|}{ Post - Test Scores } & \multirow{2}{*}{\multicolumn{2}{|c|}{$\begin{array}{c}\text { mean Grade } \\
\text { Per Grading } \\
\text { Period }\end{array}$}} \\
\hline & \multicolumn{2}{|c|}{ Addition } & \multicolumn{2}{|c|}{ Subtraction } & \multicolumn{2}{|c|}{ Total } & \multicolumn{2}{|c|}{ Addition } & \multicolumn{2}{|c|}{ Subtraction } & \multicolumn{2}{|c|}{ Total } & & \\
\hline & sum & Mean & sum & mean & sum & mean & sum & mean & sum & mean & sum & mean & $1 s t$ & $2^{\text {nd }}$ \\
\hline Control & 500 & 7.04 & 397 & 5.59 & 897 & 12.63 & 574 & 8.08 & 514 & 7.24 & 1088 & 15.32 & 82.44 & 83.73 \\
\hline Music & 583 & 6.94 & 527 & 6.27 & 1110 & 13.21 & 801 & 9.54 & 687 & 8.18 & 1488 & 17.71 & 83.25 & 84.40 \\
\hline
\end{tabular}


The sum of the pretest scores of the control group totaled 897 with a mean score of 12.63 while the sum of the pretest scores of the music group totaled 1110 with a mean of 13.21. Both the Control group (sum=500) and Music group (sum $=583$ ) have higher addition scores than subtraction scores (Control group= 397; Music group=537) while the Music group's sum of scores were higher in both addition and subtraction than that of the Control group. Comparison of the pretest and the post-test showed an increase in the scores in both addition (from 500 to 574) and subtraction (from 397 to $514)$ in the control group. The Music group registered an increase in the scores of from 583 to 801 in addition and from 527 to 687 in subtraction.

The total mean of the pretest of the control group (12.63) increased in the post test (15.32). Similarly, the pretest means of the music group also increased from 13.21in the pretest to 17.71 in the post test. The mean grade in math of both groups for the $1^{\text {st }}$ grading to second grading period also registered an increase from 82.44 to 83.73 of the control group and from 83.25 to 84.40 of the music group. This result of the comparison of the $1^{\text {st }}$ and $2^{\text {nd }}$ periodic grades in Math of the pupils which also showed significant difference in favor of the Music group strengthens and validates the effect of the experiment in causing emotional learning or additional learning brought about by happy emotion. It should be noted that the enhancement module was implemented during the second grading period and if there were significant improvements in the pupils' performance in addition and subtraction brought about by the experiment, these would likely show in and affect the second periodic grade of the pupils which it actually did.

\section{b. There were statistically significant differences on the performances of the experimental and control groups}

Table 6. Paired T-Test of Pre and Post Tests Addition, Subtraction and Total scores with $1^{\text {st }}$ and second grading grades of the control group and the Music Group

\begin{tabular}{lccccc}
\hline Groups & mean & $s d$ & $t$ & $d f$ & sig (2tailed) \\
\hline Control Group & & & & & \\
Addition & -1.04 & 1.23 & -7.04 & 70 & .000 \\
Subtraction & -1.65 & 1.86 & -7.47 & 70 & .000 \\
Total & -2.07 & 2.48 & -9.13 & 70 & .000 \\
Grade & -1.29 & .96 & -8.67 & 40 & .000 \\
& & & & & \\
Music Group & -2.60 & 1.07 & -22.32 & 83 & .000 \\
Addition & -1.91 & 2.06 & -8.46 & 83 & .000 \\
Subtraction & -4.50 & 2.29 & -18.02 & 83 & .000 \\
Total & -1.23 & 4.30 & -2.60 & 82 & .011 \\
Grade & & & & & \\
& & & & & \\
Control Group Vs Music Group & -1.563 & 1.601 & -8.227 & 70 & 000 \\
Addition & -.014 & 3.319 & -.036 & 70 & .972 \\
Subtraction & -1.577 & 3.850 & -3.453 & 70 & .001 \\
Total & -.915 & 1.850 & -4.170 & 70 & .000 \\
Grade & & & & & \\
\hline
\end{tabular}

Table 6 showed that the experimental group (music group) registered statistically significant improvements in their overall performance over the control group $(\mathrm{t}(70)=-3.50, m=-1.58, s d=3.90$, $p=.001)$. The null hypothesis is thus rejected. There was statistical difference in the performance of the music group over the control group at .05 significant level. This finding was also supported by the statistically significant difference in the subjects' periodic grade $(t(70)=-4.20, m=-.92$, $s d=1.90, p=<.001)$. So, even though there were observed improvement in the performance of the control group in addition $(t(70)=-7.04, m=-1.04, s d=1.23, p=<.001)$, Subtraction $(t(70)=-7.47$, $m=-1.65, s d=1.86, p=<.001)$ and grades $(t(40)=-8.67, m=-1.29, s d=.96, p=<.001)$ that were all statistically significant, the overall performance of Music group was better. There is statistical 
evidence to claim that happy emotion induced by music improves performance or caused positive emotional learning in Addition and Subtraction of the pupils.

The results in the comparison of the difference between the pretest and the post-test showed an increase in the scores in both addition and subtraction in the control group and the music group. This could be interpreted that both groups have similar initial knowledge in addition and subtraction. These could also be the effect of the K-12 program of the Department of Education that required every pupil to undergo kindergarten before they are accepted in grade 1 . The concepts of addition and subtraction are introduced in kindergarten. It was understandable that the teaching of addition and subtraction over time caused an increase in performance. However, the difference in the increase on the posttest in favor of the music group showed that the use of background music in instruction improved the performance better than the current practice of not utilizing music or emotions in instruction. This showed that the effect cannot be attributed to the instruction otherwise there would be no significant difference since both groups were taught the same lessons rather it can be attributed to the intervention or the use of the emotion-based teaching aids using music to induce happy emotion. This effect was further supported by the increase in the mean grade in math of both groups for the first grading to the second grading period in favor of the music group which only strengthen the claim that the effects happy emotion was not ephemeral but lasting.

The fact that the control group's score and the music group's score in addition were higher than the subtraction scores of the control group and the music group could be due to the common practice of teaching Filipino children with addition first and subtraction later. Most children know already how to add when they entered grade 1 but have difficulties in subtraction as reflected in the pre-test results.

In sum, even though there were improvements in the performance of the control group, the music group registered statistically significant improvements over the control group in addition and, subtraction which was also found and validated in the pupils' periodic grades. This finding strengthened the claim that the use of background music can improve the performance of grade 1 Filipino pupils in addition and subtraction. It follows that the present method of teaching mathematics could be further improved by inducing happy emotion through background music.

These results on research question 2 were in conjunction with the researches with the findings that emotions influence learning (Pekrun \& Linnenbrink-Garcia, 2014) and the cognitive processes (Izard, 2009). The performance of the music group was better since the emotion induced by background music was positive emotion which was found to have a positive effect in learning and performance. For positive emotions have been shown to generate solutions that require thinking beyond the immediate setting and to broaden the mind and make an individual more likely to notice details of their surroundings (Gable \& Harmon-Jones, 2010). This finding on the effectiveness of background music in inducing the required emotional states that improves learning have already been previously established by the study of Westermann, et al., (1995) and Bogert, et al. (2016). The influence of music, according to Miendlarzweska and Trost (2014), has been shown to be far reaching in its impact on the human condition, socially, personally, and intellectually (Hallam, 2010).

The ability of Music to increase or decrease arousal is mostly influenced by the tempo of a song (Husain, Thompson \& Schellenberg, 2002). It appeared that because the music used in this study were of the right tempo and mode, they were able to evoke the appropriate arousal and mood (happy) in the learner that effected the improved performance in addition and subtraction. Furthermore, the current finding on the background music's ability to induce emotion that improved the performance of the pupils was also consistent with other studies that found music to develop sufficient arousal that impacted on learning (Heuer \& Reisberg, 1990) and that listening to background music influences arousal and mood (Schmidt \& Trainor, 2001). Furthermore, the current finding is consistent with the concept that positive moods results to better learning outcomes (Isen, 2002) while negative mood or boredom hinders learning (Pekrun, 2006). The improved results in pupil's performance may be loosely attributed to the music that were used to induce the happy emotion during the teaching of addition and subtraction (Heuer \& Reisberg, 1990). The claim that humans are emotional beings and that learning is an emotional act may be handy in explaining this improved performance of grade 1 in math (Fredrickson et al., 2008). If this was so, then happy 
emotions should be utilized constantly especially in early childhood education (Arguedas, et al., 2016) and teachers may utilize other inducers of happy emotions aside from music may expect the same results because it was not music that caused the improved performance but happy emotion. Indeed, similar avenues of inducing happy emotion should be explored since Chow, Davids, Hristovski, Araújo and Passos (2011) suggested that learning occurs when the dynamic system (the pupil) becomes unstable as caused by changes in the environment may prompt the pupil to search for functional solution to the new constraints brought about by these changes in the environment.

Moreover, it could be inferred that the reason why Filipino pupils have low performance in math was perhaps the current methods of teaching math were threatening to these Filipino pupils. They may have felt threatened by the need to achieve high in mathematics as expected by Philippine society that creates math anxiety. Another reason could be the unhampered use of math teachers of reductionism and the disregard of the pupils' negative feelings in learning math. These may have been the reason why the control group only managed to get a score of 897 in the pre-test and 1088 in the posttest while the music group had 1110 in the pre-test and 1488 in the post test. The increase in performance was only 191 in the control group which was 187 points lower than the 378 of the music group. These pupils may have performed less because their emotions were disregarded in the classroom and considered only as a distraction by their teachers. The discrete negative emotions found to be important in academic context should be addressed including anxiety, fear, frustration, anger, boredom, sadness, shame, hopelessness, guilt and embarrassment (Rowe et al, 2015). Furthermore, researchers had shown the fear led to avoidance behavior (Kuhbandner, Spitzer \& Pekrun, 2011) and that anger in undermined motivation and task-irrelevant thinking (Pekrun et al., 2004). All these were addressed by utilizing happy emotion in the teaching of math through emotionbased teaching aids which was not availed of by the control group. Finally, the results of this study showed that when emotion-based teaching aids were used in the classroom, the performance of the pupils in addition and subtraction significantly improved.

The better performance of the experimental groups may be due to the characteristics of emotion- based teaching aids which used actual things and real situations that the pupils experienced and sensed every day (Baroody, 2001). The emotion -base teaching aids may have also addressed the emotional needs of the pupils by consciously inducing happy emotion to counteract the negative emotions that could be hindering the pupils' learning as suggested by Um et al. (2012) and by being constantly aware that emotions constitute potent, pervasive, predictable, sometimes harmful and sometimes beneficial drivers of decision making (Lerner et al., 2015). Furthermore, the teaching aids were developed consistent with the tenets of cognitive emotional theory of Joni Mäkivirta (2002) and the systems dynamic theory of Thelen (2005), that addressed the need of the pupils for systematic, nonlinear and dynamic development which were applied in the lessons and exercises. Moreover, the emotion-based teaching aids treated the pupils as systems who are self-organizing embodiment and knowledge creators. Pupils were not just asked to receive ready information or told by the teacher. Pupils were not considered as only the product of the environment solely controlled by the teacher but as active participants in the search for learning and creation of meaning from their own experience. The teachers were asked in the implementation of the teaching aids to address the individuality of the pupils by recognizing what the pupils feel and not only what they know. Aside from this, the teachers acted as concept assimilators and creativity facilitators and not the sole source of knowledge or the center of the educative process. They fostered conceptual manipulation, by providing relevant emotional experience and by promoting sharing of created knowledge and putting much credit on the pupils' concept creation, creativity, emotional expression and conceptual manipulation skills by defining learning through positivity, openness and tolerance for ambiguity (Mäkivirta, 2002).In addition, the teaching aids proved to be effective it were designed to softly assemble the necessary mathematical competencies, (Thelen, 2005) allowed the pupils to create their own meaning, to use their own creativity and to recognize their emotions and address them (Boekaerts, 2002), to use expanded form to explain the meaning of addition and subtraction using appropriate strategies. Finally, the teaching aids emphasized emotional expression and conceptual manipulation of skills, positivity openness and tolerance which may have led to the better performance of these pupils. (Chow, Davids, Hristovski, Araujo \& Passos 2011). 


\section{CONCLUSION}

Based from the findings of this study, the following conclusions were induced:

1. There are Filipino music that can actually induces happy emotion which may be utilized in the emotion-based teaching aids.

2. Happy emotion induced by some Filipino children's music can and were found to improve the performance of grade 1 Filipino pupils in addition and subtraction.

3. Teaching aids which utilized the principles, characteristics and strengths of emotion- based learning are promising alternatives to other cognitive-based strategies in improving children's performance in math.

\section{RECOMMENDATIONS}

This study recommends to policy makers to formulate guidelines in the effective utilization of emotion-based teaching inside and outside the classrooms so that the use of emotion-based teaching and learning will become institutionalized.

The study further recommends that math teachers especially in early childhood education to take cognizance of these findings and be emboldened in the use of emotion-based teaching so that their pupils will benefit from it by performing better not only in math but in life since it was commonly accepted that early childhood education affects future performance. Teachers are encouraged to create better classroom learning environment by using music to induce happy learning atmosphere and to make their pupils happy so that instead of unconsciously developing math anxiety, they shall develop at the early stage a love for mathematics. Aside from this, the text books, learning materials and teaching aids in math should also be developed utilizing the principles of emotion-based teaching and the power of emotions in effecting better learning. Furthermore, school management should encourage teachers to use emotion-based teaching by tapping the benefits of positive emotions in mathematics to develop emotive learning skills- the skill to use emotion towards better learning.

The study also recommends that the Philosophy of Education of the Philippines, the Department of Education's Mission/Vision and the school organizations' goals and directions should be reviewed and set clearly to achieve competence, excellence and global competitiveness through both mental and emotional developments utilizing the potent role of emotions in the teachinglearning process to make education more human, humane and holistic.

Lastly, further study is recommended using related or other variables and inducers to induce different positive emotions in an attempt to improve the performance of Filipino children on the four basic mathematical skills and other foundation skills.

\section{REFERENCES}

Arguedas, M., Daradoumis, A., \& Xhafa, F. (2016). Analyzing how emotion awareness influences students' motivation, engagement, self-regulation and learning outcome. Educational Technology and Society, 19(2), 87-103.

Baroody, A. J., \& Benson, A. (2001). Early childhood corner: Early number instruction. Teaching Children Mathematics, 8(3), 154-159.

Bauer, P., Stennes, L., \& Haight, J. (2003). Representation of the inner self in autobiography: Women's and men's use of internal states language in personal narratives. Memory, 11(1), 27-42.

Blair, J., Czaja, R. F., \& Blair, E. A. (2013). Designing surveys: A guide to decisions and procedures. Sage Publications.

Boekaerts, M. (2002). Bringing about change in the classroom: Strengths and weaknesses of the self-regulated learning approach-EARLI Presidential Address, 2001. Learning and Instruction, 12(6), 589-604.

Bogert, B., Numminen-Kontti, T., Gold, B., Sams, M., Numminen, J., Burunat, I., ... \& Brattico, E. (2016). Hidden sources of joy, fear, and sadness: explicit versus implicit neural processing of musical emotions. Neuropsychologia, 89, 393-402. 
Chow, J. Y., Davids, K., Hristovski, R., Araújo, D., \& Passos, P. (2011). Nonlinear pedagogy: Learning design for self-organizing neurobiological systems. New Ideas in Psychology, 29(2), 189-200.

Deasy, R.J. (2002). Critical links: learning in the arts and student academic and social development. Washington, D.C: Arts Education Partnership. Department of Education. 2013. State of Education 2012- 2013. Presentation.

Diener, E., \& Biswas-Diener, R. (2008). Happiness: Unlocking the mysteries of psychological wealth. New Jersey, NJ: John Wiley \& Sons.

Dolegui, A. S. (2013). The impact of listening to music on cognitive performance. Inquiries Journal, 5(09). Fredrickson, B. L., Cohn, M. A., Coffey, K. A., Pek, J., \& Finkel, S. M. (2008). Open hearts build lives:

positive emotions, induced through loving-kindness meditation, build consequential personal resources.

Journal of personality and social psychology, 95(5), 1045.

Gable, P., \& Harmon-Jones, E. (2010). The blues broaden, but the nasty narrows: Attentional consequences of negative affects low and high in motivational intensity. Psychological Science, 21(2), 211-215.

Gardiner, M.F. (2000). Music, learning, and behavior: A case for mental stretching. Journal for Learning Through Music. 72-93

Hallam, S., Price, J., \& Katsarou, G. (2002). The effects of background music on primary school pupils' task performance. Educational Studies, 28(2), 111-122.

Hareli, S., \& Parkinson, B. (2008). What's social about social emotions? Journal for the Theory of Social Behaviour, 38(2), 131-156.

Helmrich, B. H. (2010). Window of opportunity? Adolescence, music, and algebra. Journal of Adolescent Research, 25(4), 557-577.

Hetland, L. (2000). Learning to make music enhances spatial reasoning. Journal of Aesthetic Education, 34(3/4), 179-238.

Heuer, F., \& Reisberg, D. (1990). Vivid memories of emotional events: The accuracy of remembered minutiae.

Memory \& Cognition, 18(5), 496-506.

Husain, G., Thompson, W. F., \& Schellenberg, E. G. (2002). Effects of musical tempo and mode on arousal, mood, and spatial abilities. Music Perception: An Interdisciplinary Journal, 20(2), 151-171.

Isen, A. M. (2002). A role for neuropsychology in understanding the facilitating influence of positive affect on social behavior and cognitive processes. Handbook of Positive Psychology, 528-540.

Izard, C. E. (2009). Emotion theory and research: Highlights, unanswered questions, and emerging issues.

Annual Review of Psychology, 60, 1-25.

Izard, C., Stark, K., Trentacosta, C., \& Schultz, D. (2008). Beyond emotion regulation: Emotion utilization and adaptive functioning. Child Development Perspectives, 2(3), 156-163.

Jocano, F. (2000). Filipino Value System. Punlad Research House Quezon City:.p. 68

Jordan, N. C., Kaplan, D., Locuniak, M. N., \& Ramineni, C. (2007). Predicting first-grade math achievement from developmental number sense trajectories. Learning Disabilities Research \& Practice, 22(1), 3646.

Jordan, N. C., Kaplan, D., Ramineni, C., \& Locuniak, M. N. (2009). Early math matters: Kindergarten number competence and later mathematics outcomes. Developmental psychology, 45(3), 850.

Kim, J., Wigram, T., \& Gold, C. (2009). Emotional, motivational and interpersonal responsiveness of children with autism in improvisational music therapy. Autism, 13(4), 389-409.

Kuhbandner, C., Spitzer, B., \& Pekrun, R. (2011). Read-out of emotional information from iconic memory: The longevity of threatening stimuli. Psychological Science, 22(5), 695-700.

Lerner, J. S., Li, Y., Valdesolo, P., \& Kassam, K. S. (2015). Emotion and decision making. Annual review of psychology, 66, 799-823.

Liew, T. W., \& Tan, S. M. (2016). The Effects of Positive and Negative Mood on Cognition and Motivation in Multimedia Learning Environment. Educational Technology \& Society, 19 (2), 104-115.

Mäkivirta, J. (2002). Cognitive Emotional Learning. Journal of Cognitive Pedagogy. 1, 12-40.

McEwing, H. E. (2011). Music, movement, and early literacy: A best practices primer for" gotta move!".

Children \& Libraries, 9(2), 29.

Mulac, A., Bradac, J. J., \& Gibbons, P. (2001). Empirical support for the gender-as-culture hypothesis: An intercultural analysis of male/female language differences. Human Communication Research, 27(1), 121- 152.

North, A. C., Hargreaves, D. J., \& O'Neill, S. A. (2000). The importance of music to adolescents. British Journal of Educational Psychology, 70(2), 255-272.

Park, B., Flowerday, T., \& Brünken, R. (2015). Cognitive and affective effects of seductive details in multimedia learning. Computers in Human Behavior, 44, 267-278. 
Pekrun, R. (2006). The control-value theory of achievement emotions: Assumptions, corollaries, and implications for educational research and practice. Educational Psychology Review, 18(4), 315-341.

Pekrun, R., \& Linnenbrink-Garcia, L. (2014). Introduction to emotions in education. In International handbook of emotions in education (pp. 11-20). England, UK: Routledge.

Pekrun, R., Goetz, T., Perry, R. P., Kramer, K., Hochstadt, M., \& Molfenter, S. (2004). Beyond test anxiety: Development and validation of the Test Emotions Questionnaire (TEQ). Anxiety, Stress \& Coping, 17(3), 287-316.

Pekrun, R., Vogl, E., Muis, K. R., \& Sinatra, G. M. (2017). Measuring emotions during epistemic activities: the Epistemically-Related Emotion Scales. Cognition and Emotion, 31(6), 1268-1276.

Perham, N., \& Currie, H. (2014). Does listening to preferred music improve reading comprehension performance? Applied Cognitive Psychology. 28: 279-284. Published online 6 January 2014 in Wiley Online Library. Doi: 10.1002/acp.2994.

Roberts, D. F., \& Christenson, P. G. (2001). Popular music in childhood and adolescence. Handbook of Children and the Media, 395-413.

Rowe, A. D., Fitness, J., \& Wood, L. N. (2014). The role and functionality of emotions in feedback at university: A qualitative study. The Australian Educational Researcher, 41(3), 283-309.

Rowe, A. D., Fitness, J., \& Wood, L. N. (2015). University student and lecturer perceptions of positive emotions in learning. International Journal of Qualitative Studies in Education, 28(1), 1-20.

Schmidt, L. A., \& Trainor, L. J. (2001). Frontal brain electrical activity (EEG) distinguishes valence and intensity of musical emotions. Cognition \& Emotion, 15(4), 487-500.

Schutz, P. A., Hong, J. Y., Cross, D. I., \& Osbon, J. N. (2006). Reflections on investigating emotion in educational activity settings. Educational Psychology Review, 18(4), 343-360.

Schwartz, R. W., Ayres, K. M., \& Douglas, K. H. (2017). Effects of music on task performance, engagement, and behavior: A literature review. Psychology of Music, 45(5), 611-627.

Seligman, L. (2011). Diagnosis and treatment planning in counseling. Springer Science \& Business Media.

Simon, R. W., \& Nath, L. E. (2004). Gender and emotion in the United States: Do men and women differ in self-reports of feelings and expressive behavior?. American Journal of Sociology, 109(5), 1137-1176.

Singh, M., Singh, M. M., \& Singhal, N. (2013). Ann based emotion recognition. Emotion, 1, 56-60.

Slater, J., Strait, D. L., Skoe, E., O'Connell, S., Thompson, E., \& Kraus, N. (2014). Longitudinal effects of group music instruction on literacy skills in low-income children. PLoS One, 9(11), e113383.

Suárez-Pellicioni, M., Núñez-Peña, M. I., \& Colomé, À. (2016). Math anxiety: A review of its cognitive consequences, psychophysiological correlates, and brain bases. Cognitive, Affective, \& Behavioral Neuroscience, 16(1), 3-22.

Tendler, A., \& Wagner, S. (2015). Different types of theta rhythmicity are induced by social and fearful stimuli in a network associated with social memory. Elife, 4 , e03614.

Thelen, E. (2005). Dynamic systems theory and the complexity of change. Psychoanalytic Dialogues, 15(2), 255-283.

Thompson, W. F., Schellenberg, E. G., \& Letnic, A. K. (2012). Fast and loud background music disrupts reading comprehension. Psychology of Music, 40(6), 700-708.

Tyng, C. M., Amin, H. U., Saad, M. N., \& Malik, A. S. (2017). The influences of emotion on learning and memory. Frontiers in psychology, 8, 1454.

Um, E., Plass, J. L., Hayward, E. O., \& Homer, B. D. (2012). Emotional design in multimedia learning. Journal of Educational Psychology, 104(2), 485.

Vail, P. (2016). The role of emotions in learning. Retrieved February 17, 2017, http://www.greatschools.org/gk/author/priscillalvailmat/

Weare, K. (2004). The international alliance for child and adolescent mental health and schools (INTERCAMHS). Health Education, 104(2), 65-67.

Westermann, R., Spies, K., Stahl, G., \& Hesse, F. W. (1995). Relative effectiveness and validity of mood induction procedures: A meta-analysis. European Journal of Social Psychology, 26(4), 557-580. 